\title{
LINGUISTICS AND CULTURAL STUDIES INTEGRATION INTO SOCIAL AND POLITICAL SCIENCE COURSE
}

\author{
Wojciech Pomykalo, \\ High School of Management in Warsaw, Poland, \\ wojtekfranciszek@wp.pl \\ Oksana Omelchenko \\ University of Contemporary Knowledge, Kyiv, Ukraine \\ omeltchenko@ukr.net
}

\begin{abstract}
This article reveals the meaning and content of the linguistic and cultural studies integration into social and political science course in the training of future politicians. The article reflects the importance of linguistic and cultural studies for the formation of language competence of students as well as skills of political communication, for understanding the characteristics of the country's social and political issues. The interdisciplinary approach emphasises the relationship in the study of linguistic, cultural, and political agenda, characterises the interdisciplinary essence of regional studies. The critical discourse analysis (CDA) of political texts was chosen as the key methodological strategy for the efficient development of political communication and problem-solving skills. The authors propose the implementation of a special interdisciplinary course for the first-year students majoring in philology and political studies, focused on the studying the political and cultural features of a language-targeted country by means of CDA. We compared the results of students' political communication skills development prior and post- course period and we observed the improvement according to the following criteria: perception of the vocabulary and functional language structures (by 17\%); analysis of cultural and political agenda from the explicit and implicit language structures (by 23\%); text annotation (by 50\%); text production, distribution and target audience analysis (by 10\%). Moreover, it was observed that CDA implementation facilitated the development of critical thinking skills as well as the skills of texts decoding.
\end{abstract}

Keywords: linguistics; cultural studies; culture; political communication; critical discourse analysis (CDA).

\section{Introduction}

In the process of integration into the European educational and cultural space, the issues of introducing students to the world of culture and politics are vital for future politicians and ambassadors. It is obvious that socio-economic transformations of society are closely related to raising the cultural level of the individual and society, since culture acts as a universal mechanism for the formation of personality, social attitudes and priorities. In a developed political and cultural space a person with a sense of responsibility is able to think critically, appreciates intellectual and material wealth, respects the personality and strives for self-realisation.

The assimilation of national cultural and historical values includes an awareness of the harmony of the international and national beliefs and cultural achievements. Our research involves studying the psychological and pedagogical aspects of teaching and outlines the linguistic potential of educational material in the classroom. This allows formulating the purpose of research - to identify methodological tools that enhance the development of critical discourse analysis (CDA) and perspective-taking skills with the emphasis on the political and cultural context of the discourse. The hypothesis of the research is based on the assumption that the implementation of the culture and language interdisciplinary course with the emphasis on CDA elements for the first-year students will enhance the level of language awareness, understanding of sociopolitical and cultural realities, as well as develop CDA skills.

\section{Theoretical background}

A great number of scientific sources substantiate the relevance and usefulness of linguistics and cultural studies integration, but scientific research of the relationship between the study of linguistics and regional geographic themes on the basis of political discourse is not enough developed. The nature of the interrelationships of universal, international and national issues is reflected in the concept of "multicultural education" and represents learning in the form of a "dialogue of cultures" (Bibler, 2016). This concept implies the inclusion of topics on the national mentality, political issues and culture into the foreign language curriculum. The programmes of country studies for foreign students and immigrants are widespread (Grahamet al, 2009; Morska, Horpinich, \&Olendr, 2018). They provide a general overview of the specifics of a country: geography, culture, political agenda. However, the programmes do not suggest an in-depth critical analysis of the mentality of the nation, its influence on state policy and the mentality reflection in the language discourse. 
At the present stage of the development of linguistic science, there are trends towards interdisciplinary integration in teaching linguistics. Cultural factors (ethnic, national and civilisation processes) are recognised as decisive in the context of studying political phenomena as they focus on people's interaction in terms of their moral and national values, norms, habits and traditions. Each culture demonstrates indicative religious, mental, political, legal and other forms of social relations. Thus, sociocultural, critical linguistic and extralinguistic analysis determines and reflects the political realities of the country expressed through linguistic strategies.

The intercultural education is under the influence of the national culture reflected in the social environment. This process of socialisation combines education and adaptation to a given society, as a result, the individual accepts the native culture, learns to act within the framework of generally accepted rules of behaviour, and acquires features of the national political behaviour.

With this in mind, the intercultural education researchers suggest the educational model designed to analyse the specifics of foreign language and cultural studies integration. The model comprises the following components: 1) general cultural information (knowledge of history, geography, general information); 2) behavioural culture (relationships in society, norms, values, etiquette, traditions); 3) cultural heritage (art values). Teaching linguistics and cultural studies should comprise all these components (Angel, 2014; Starfield, 2014). Political communication has become the most important factor determining the development of social ties, the degree of society consolidation, the level of legitimacy of government institutions, means of expression of political demands and coordination of political interests, as well as a resolution of political conflicts. The level and format of socio-political communication can serve as an indicator of the political system stability. Political communication promotes the development of analytical, critical thinking, predicting and problem-solving skills which will help to frame and to correlate phenomena and events within international politics, identify and design solutions to complex inter-ethnic and inter-religious conflict relations, analyse phenomena and events in international politics, develop adequate interpretations of specific processes and strategies.

CDA is closely connected and applied in studying the political and social texts and their potential impact on the society. Through this approach, the language is considered as a power source that reflects ideology, political and cultural identities dominant in a society. Therefore, the choice of language interlocutors is crucial for the perception and understanding of authors' intentions or editors' political background that are substantiated by the historical settings and influence the political and cultural tendencies in the community. van Dijk (2015) emphasises the significance of CDA for the disclosure of power relations and issues of prejudices, injustice or inequalities. In his opinion, critical reading and understanding of the implicit political messages provide the balance between editors' and readers' perception of social issues. van Dijk's approach allows combining cognitive, social and linguistic theories to interpret and reproduce the ideology through everyday media discourse.

According to Wodak and Meyer (2001), CDA focuses on interdisciplinary methodology, descriptive and interpretive language and logic of the discourse, problem-oriented issues, the assumption that power relations are discursive and discourses are situated in time and place; the view that language tools are never neutral.

Fairclough (1995) introduced the concept of CDA in his work Language and Power (1995) where he states that language should be analysed as a social practice in both spoken and written discourse. The scholar developed a three-dimensional framework for CDA: analysis of (spoken or written) language texts, analysis of discourse practice (processes of text production, distribution and consumption) and analysis of discursive events as instances of sociocultural practice. In our course, we applied only two components of the CDA: linguistic text analysis and discourse practice as we consider these elements are correlated with students language and sociopolitical literacy background.

The methodological basis of the research is a multicultural approach to education, suggested by Roth (2010). The approach focuses on the preservation and development of cultural differences in the process of language studies. In politics, this theory is called multiculturalism and involves a gradual adaptation to the realities of the social environment by means of the language as a tool of interpersonal communication (Olusegun, 2015) and the spiritual value of society, as well as a mechanism of social and cultural heredity.

In our research, we applied the comparative analysis of philosophical, psychological, pedagogical and political literature on the problem. In order to verify the practical results of the experiment, we carried out the following empirical methods: testing, interview and observations. Students $(\mathrm{N}=30)$ of the first year studying at the University of Contemporary Knowledge (Kyiv, Ukraine) majoring in philology and political 
studies took part in our experiment. Students were randomly distributed into the control and experimental groups, 15 students in each. We developed the course on country studying with the elements of critical linguistics in the experimental group before students are introduced with field related subjects. The experimental course was integrated into the interdisciplinary bachelor's programme in European Studies which combines studies in foreign languages with History and Political Science courses taught to first-year students. The course comprises 72 practical hours (about 3 months): 2 classes per week of 90 min duration each. The course is focused on studying the social, ethnic and political agenda of a particular country, whose language is studied.

We did not perform the initial test on the language level as we have the results of the National Exam on foreign language. However, we proposed students the extended test after the course implementation that included CDA of a text on a political topic and annotating the scientific article. Moreover, students were assessed not only according to the results of the test, but they also had to perform the language and culture project that validates the level of acquisition of political and multicultural discourse functional language as well as perspective-thinking abilities. The main task of the project is to compare and analyse texts on one topic from different ideological editions and predict the impact of the text on the society. At the end of the first course, students pass a Foreign Language exam, which includes questions based on the material and knowledge students have acquired during the course.

As a result of successful implementation of the course over three years $(2016,2017,2018)$ at the department of the Translation Theory and Practice of the University of Modern Knowledge along with a high evaluation by the external examiners ( 5 members of the faculty), the academic discipline has become an integral part of the education and research programmes for students majoring in Philology and Political Studies.

\section{Results}

A special place in our experiment was given to the selection of "specific" linguistic-cultural and ethnoor sociopolitical contexts that were under CDA. The selection principle was based on the following criteria: a) availability of the sources for the target audience; b) description of social and political tendencies using explicit and implicit language structures; c) inclusion of historical facts known to native speakers; d) significance and popularity of the source in the society. The CDA of such texts presupposes knowledge of the language, but also the need for simultaneous studying national (cultural, political, and social) realities and language strategies of critical linguistics. During the implementation of our course, we introduced students such critical linguistics strategies as nominalisation, passivisation, anaphoric reference, implicit and explicit expressions, foregrounding and backgrounding etc.

The post-course test results show that students who had attended a Linguistics and Cultural Studies course demonstrated better results. The table 1 shows the results of the tests before and after the course:

\section{Pre- and post- course assessment results}

Table 1

\begin{tabular}{|l|c|c|}
\hline \multicolumn{1}{|c|}{ Criteria of assessment } & $\begin{array}{c}\text { Pre- course results } \\
\text { (students number) }\end{array}$ & $\begin{array}{c}\text { Post -course } \\
\text { results } \\
\text { (students number) }\end{array}$ \\
\hline $\begin{array}{l}\text { Perception of the vocabulary and } \\
\text { functional language structures }\end{array}$ & 22 & 27 \\
\hline $\begin{array}{l}\text { Analysis of cultural and political agenda } \\
\text { from the explicit and implicit language } \\
\text { structures }\end{array}$ & 20 & 27 \\
\hline Text annotation & 15 & 30 \\
\hline $\begin{array}{l}\text { Text production, distribution and target } \\
\text { audience analysis }\end{array}$ & 21 & 24 \\
\hline
\end{tabular}

From the table it can be seen that students performed a deeper and more professional critical and discourse analysis of the text through the text as well as during the project performance: perception of the vocabulary and functional language structures of social and political content improved by 17\%; understanding and reflection of the current cultural and political agenda from the explicit and implicit language structures (syntactic analysis, use of metaphor and rhetorical devices) and context increased by 23\%; a number of students who successfully performed text annotation with elements of national semantic 
features and cross-cultural information rose by 50\%; students' skills of text production, distribution and target audience analysis enhanced by $10 \%$.

The interviews with European Studies programme examiners about the course results proved our hypothesis that the course had allowed participants to gain systematic knowledge and apply their acquired knowledge and skills in practice.

\section{Discussion}

The linguistic and cultural approach to teaching a foreign language aims at integrated studying language and culture due to a cumulative social function of a language where it acts as a link between generations and serves as a means of transmitting collective experience. Thus, there is a need for implementing regional approach into FL classroom as future politicians should be familiar with the politics and culture of the targetlanguage country, development of international contacts, strengthening of interethnic relations in the economy, politics and culture.

However, we believe that Linguistics and Cultural Studies is not just a course of lectures in a foreign language, but a special discipline that promotes learning a foreign language and solving social adaptation problems, increasing the amount of cultural background knowledge, ensuring successful communication in the language, understanding the political and socio-political realities of the country. Our research results are in line with the ideas of Stanley (2013) that Linguistics and Cultural studies include not only vocabulary, national culture and traditions, but also perform an enormous educational function, instil respect and appreciation to the target language country.

The rapid development of international relations in the political, economic, cultural and other areas entails the focus of modern methods of teaching foreign languages on the real life conditions of communication. The characteristics of communication are determined by the living conditions of people, political and cultural factors, and the socio-political structure of society. Therefore, the communicative competence implies not only the appropriate foreign language communication techniques, but also the use of large non-linguistic (extralinguistic) information that is necessary for consistent understanding between people to solve various problems in the socio-political sphere.

We can single out one of the most rational ways to solve this problem today. Researchers (Chambers, 2005; Roth, 2010; Stanley, 2013) agree that the humanisation of education is one of the possible solutions, which means the full involvement of students in the cultural heritage and values. The humanistic orientation of education requires a significant revision of all the goals and technologies of the whole process of learning foreign languages, as a new way of intercultural communication and intercultural understanding.

Currently, there are two approaches to teaching linguistic and cultural aspects in science: socio-political and philological. The socio-political approach is implemented through the political disciplines that are associated with the study of foreign languages; philological approach involves the study of the structure of a foreign language: words, phrases, texts, poems (Aljiffri, 2010).

It is worth mentioning that due to the course, we introduced the elements of Critical Linguistics and CDA to students, that is vital for future politicians. CDA is a method of the textual analysis that reveals the role of language in defining social and political relations hiding asymmetrical lines demonstrating the interconnections of political agenda, ethnicity, disparity and religion reproduced in a text. It is important because such texts are read by nations and impact their behaviour and prevent misunderstanding and misinterpretation of the context. The CDA approach allows considering the ways language is employed to represent different understandings and world views (Partridge, 2012).

Thus, the key method of our course that promotes CDA is comparing of texts connected by one topic but published by different mass media editions. It is obvious that the same information can be interpreted in a different way considering newspaper editorials insights, understanding of the perspectives and attitude to a political situation. It is explained by the fact that preconception can affect discourse perception and it might be unnoticed except by experts or targets of the message. The ambivalent nature of discourse analysis and understanding of its tools allow establishing the difference in language, culture or social identities in a tolerant way analysing social encounters. Our research ideas are supported by Eggins (2004)who states that "a higher level of context to which increasing attention is being given within systemic linguistics is the level of ideology...[j] ust as no text can be free of context (register or genre), so no text is free of ideology. In other words, to use language at all is to use it to encode particular positions and values"(pp.10-11). Therefore, our course is aimed at teaching students to understand how the same meaning can be changed and presented in different texts in terms of ethno-political agenda, power, religion and ideology. The course provides students with knowledge of descriptive accounts of the written discourse structures and strategies considered as a form of sociocultural practice and to analyse the relationships of text features considering its production, 
processing and consumption. The critical factor for the successful achievement of goals is students' sociopolitical and intercultural background that is provided by the suggested course.

Due to our course, students learn how to identify whether the media suggests a solution or a cause of a problem, how to trace the development of community biased ideology by means of linguistic expressions and to reveal the themes and strategies newspaper editorials use to demonstrate their linguistically enclosed ideological and attitudinal positions.

\section{Conclusions}

Thus, we can draw the following conclusions. Linguistics and Cultural Studies is an important discipline in the system of teaching a foreign language, as well as a major component in the formation of communication skills and knowledge in the field of political communication. Political communication is the main mechanism for the development of the modern political processes, the leading tool for international communication. The modern nature of society development and new information and communication technologies change the old ideas, attitudes, stereotypes; affect the model of the relationship between political institutions and individuals, political behaviour. Our experiment also proved that knowledge of the vocabulary with the national semantic component and understanding of the national culture characteristics and mentality allow achieving better understanding between the interlocutors in situations of intercultural communication. The study of linguistic features of the country contributes to the understanding of social life, the communication process, civil consciousness and the political culture of the country. Linguistics and cultural studies are one of the most flexible areas, reflecting the changes taking place in society, and allow a deeper understanding of the nature of socio-political transformations.

\section{References:}

Aljiffri, I. (2010). Effects of the Integrated Approach to Teaching English and Social Studies. Journal of Educational \& Psychological Sciences, 11 (3), 11-31. Retrieved 10 January 2019 from https://sites.google.com/site/tijepa2010/home.

Chambers, A. (2005). Integrating corpus consultation in language studies.Language Learning \& Technology, 9(2), 111125. Retrieved 15 March 2019 from https://eric.ed.gov/?id=EJ846327

Dijk, T.A. (2015). Critical Discourse Analysis. In D. Tannen, H. E. Hamilton, and D. Schiffrin (Eds.), The Handbook of Discourse Analysis, Second Edition. John Wiley \& Sons, Inc.

Eggins, S. (2004) An Introduction to Systemic Functional Linguistics.London, U K:Continuum

Graham, C. R., Burgoyne, N., Cantrell, P., Smith, L., Clair St., L., \&Harris, R. (2009). TPACK development in science teaching: Measuring the TPACK confidence of in-service science teachers. TechTrends, 53(5), 70-79. https://doi.org/10.1007/s11528-009-0328-0

Angel, L. (2014). Critical Discourse Analysis in Applied Linguistics: A Methodological Review. Annual Review of Applied Linguistics. 34: 213-232. doi:10.1017/S0267190514000087

Morska, L., Horpinich, T., \&Olendr, T. (2018).Teaching Medical Students' Professional English Reading on the Basis of Individual Cognitive Learning Styles. Science and Educatin, 2, 86-93. Retrieved 10 January 2019 from dspace.pdpu.edu.ua/jspui/handle/123456789/118

Mullet, D. R. (2018).A General Critical Discourse Analysis Framework for Educational Research. Journal of Advanced Academics, 29(2), 116-142. https://doi.org/10.1177/1932202X18758260

O'Byrne, W. I., \&Pytash, K. E. (2015). Hybrid and blended learning. Journal of Adolescent \& Adult Literacy, 59(2), 137-140. https://doi.org/10.1002/jaal.463

Olusegun, B. S. (2015). Constructivism Learning Theory: A Paradigm for Teaching and Learning. Journal of Research \& Method in Education, 5(6), 66-70. Retrieved 10 January 2019 from https://www.tandfonline.com/loi/cwse2015

Rahimi, Elahe (May 2015). "Critical Discourse Analysis and Its Implication in English Language Teaching: A Case Study of Political Text". Theory and Practice in Language Studies, 5 (3), 504-511. https://doi.org/10.17507/tpls.0503.08

Roth, W. M. (2010). Learning environments research, lifeworld analysis, and solidarity in practice. Learning Environments Research, 2, 225-247.https://doi.org/12.11193/34114188-2010-2

Stanley, G. (2013). Language learning with technology: ideas for integrating technology in the language classroom. Cambridge: Cambridge University Press.

Starfield, S. (2014).Revue française de linguistiqueappliquée/Current and Future Directions in English for Specific Purposes Research. Revue française de linguistique appliquée, XIX (1), 9-14. Retrieved 15 July, 2018 from

Toolan, M. (Ed.) (2009). .Language Teaching: Integrational Linguistic Approaches. New York: Routledge. https://doi.org/10.4324/9780203882269

Wodak, R., Meyer , M. (2001). Methods of Critical Discourse Analysis. Sage Publications. 